\title{
Unimolecular Variant of the Fluorescence Turn-On Oxidative Coupling of Catecholamines with Resorcinols
}

\author{
Mariagrazia Iacomino, Maria Laura Alfieri, Orlando Crescenzi, ${ }^{\circledR}$ Marco d'Ischia, ${ }^{\circledR}$ \\ and Alessandra Napolitano*(1) \\ Department of Chemical Sciences, University of Naples Federico II, Via Cintia 4, 80126 Naples, Italy
}

Supporting Information

\begin{abstract}
Reported herein is a unimolecular variant of the fluorescence turn-on oxidative coupling of catecholamines with resorcinols ("FluoResCat") based on the easily accessible conjugate 4-(2-((2,4-dihydroxybenzyl)amino)ethyl)benzene1,2-diol (1). The process involves an alkali-activatable sequence of autoxidation and intramolecular cyclization steps with loss of carbon, leading to a fluorescent methanobenzofuroazocinone product identical to that obtained from the oxidative coupling of dopamine with

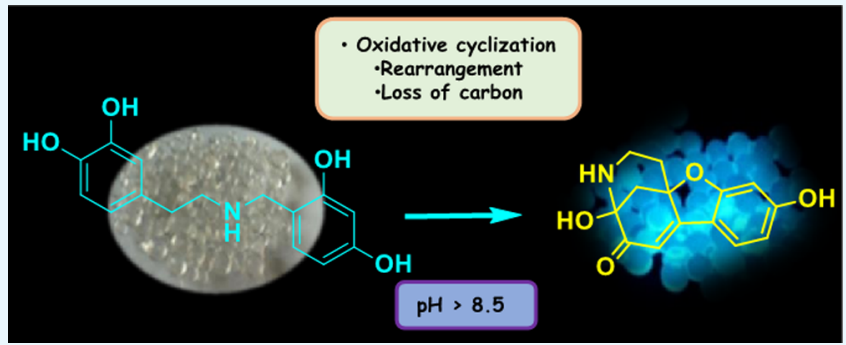
resorcinol. A mechanistic route for this unexpected reaction, mimicking the synthesis of the natural fluorophore matlaline, would involve highly constrained polycyclic spiro intermediates (liquid chromatography-mass spectrometry analysis of intermediates, model reactions, and density functional theory calculations). Emission turn-on from 1 in response to oxygen, superoxide-generating systems, or gaseous ammonia/volatile amines may be of interest for sensing applications, for example, in smart packaging.
\end{abstract}

\section{INTRODUCTION}

The ability of catecholamine compounds, for example the amino acid DOPA and dopamine, to undergo oxidative coupling with resorcinols to give a highly fluorescent product featuring a 4,9dihydroxy-3,4-dihydro- $1 H$-4,11a-methanobenzofuro [2,3-d]azocin-5(2H)-one scaffold has been extensively documented in the literature (Scheme 1). ${ }^{1}$ The resulting methanobenzofur-

Scheme 1. Oxidative Coupling of Catecholamine Compounds with Resorcinol Leading to Fluorescent Methanobenzofuroazocinone Products

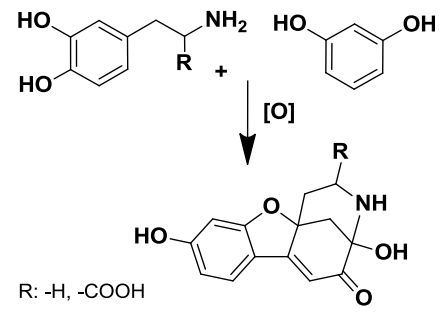

oazocinone scaffold is akin to that of monardine in matlaline, the yellow fluorescent product produced in lignum nephriticum by oxidation of Pterocarpus indicus and Eysenhardtia polystachya Cand $O-\beta$-glycosylhydroxydihydrochalcones. ${ }^{2}$ The unusual fourring structure of the natural fluorophore was confirmed by reproducing the intramolecular oxidation reaction of coatline $B$, isolated from E. polystachya, which yielded the fluorescent core (Figure 1). ${ }^{3}$ Recent studies demonstrated that the fluorophore can exist in different prototropic species, only one of which, the anion form, is responsible for the strong blue emission. ${ }^{4}$<smiles>[R]c1c(O)ccc(C(=O)C(O)Cc2ccc(O)c(O)c2)c1O</smiles>

Coatline B

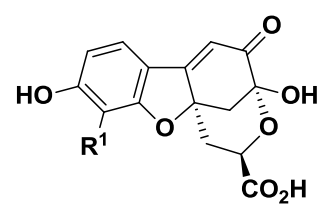

Matlaline
$R^{1}=C-\beta-D-$ glucopyranosyl

Figure 1. Structure of coatline B isolated from E. polystachya and its fluorescent oxidation product matlaline.

The high-emission quantum yield in water (approximating unity), the $\mathrm{pH}$-dependent switching between bright and dark states, and the full compatibility with aqueous solvents suggested the potential of this fluorogenic reaction for manifold applications, in particular for sensing catecholamines or alkaline conditions causing increases in $\mathrm{pH}$. In support of this, a study reporting use of this chemistry for the fast and low-cost turn-on fluorescence detection of dopamine, or for the assay of enzymatic activity, has appeared recently. ${ }^{5}$ However, a predictable practical limitation of the catecholamine-resorcinol coupling for sensing and other applications is represented by its

Received: October 12, 2018

Accepted: January 4, 2019

Published: January 17, 2019 
bimolecular character, which may weaken the fluorescence response under high-dilution conditions or in the presence of interfering species in hydrogels and complex matrices.

In attempt to exploit the fluorescence turn-on oxidative coupling of catecholamines with resorcinols ("FluoResCat") to access novel oxygen and alkali-sensing antioxidants with fluorescence read out, ${ }^{6-8}$ we designed a methylene-bridged dopamine-resorcinol conjugate, 4-(2-((2,4-dihydroxybenzyl)amino)ethyl)benzene-1,2-diol (1), that could generate the methanobenzofuroazocinone fluorophore by oxidative selfcoupling in a head-to-tail fashion. Quite unexpectedly, under slightly alkaline aerobic conditions, 1 was shown to undergo autoxidation with formation of the same methanobenzofuroazocinone fluorescent product derived from the oxidative coupling of dopamine with resorcinol. The mechanisms of the reaction, purportedly involving an oxidative rearrangement with loss of carbon, was investigated by chemical experiments and computational approaches and the potential of the system for the sensing of oxygen/volatile amines in different applications was preliminarily explored.

\section{RESULTS AND DISCUSSION}

Synthesis and Oxidation Chemistry of 1 . The dopamine-resorcinol conjugate $\mathbf{1}$ was easily obtained by condensation of dopamine with 2,4-dihydroxybenzaldehyde followed by a mild reduction step (Scheme 2 and Figures S1S6). ${ }^{6}$

Scheme 2. Synthesis of the Dopamine-Resorcinol Conjugate 1: (i) TEA (1.3 equiv) $/ \mathrm{CH}_{3} \mathrm{OH}$; (ii) $\mathrm{NaBH}_{4}$ (Excess)/ $\mathrm{CH}_{3} \mathrm{COOH}_{\mathrm{gl}}$

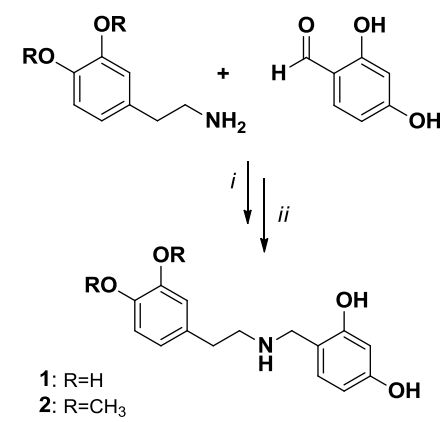

Under stirring in $0.050 \mathrm{M}$ carbonate buffer, $\mathrm{pH}$ 9.0, 1 was converted into a strongly emitting yellow species which displayed emission spectrum very close to that of the dopamine-resorcinol coupling product (Figures 2 and S7), and also in the absorption spectrum one of the maxima at 420 $\mathrm{nm}$ was closely similar to that of the product of the reaction of dopamine with resorcinol. The kinetics of the reaction was systematically investigated and it was found to be optimal in the $\mathrm{pH}$ range 8.5-9.0, similar to what can be observed for the autoxidation of catecholamines. At $\mathrm{pHs}$ below 7.0, the reaction did not proceed appreciably.

HPLC-UV analysis of the oxidation of 1 revealed the presence of a component absorbing at $280 \mathrm{~nm}$ corresponding to 1 , which was slowly consumed to below detection limits at $3 \mathrm{~h}$ with concomitant formation of a new more retained species absorbing at $390 \mathrm{~nm}$. This latter proved to be identical to the one produced by the oxidation of dopamine and resorcinol (Figure S7). Liquid chromatography-mass spectrometry (LC-MS) electrospray ionization $\left(\mathrm{ESI}^{+}\right)$analysis of the oxidation mixture

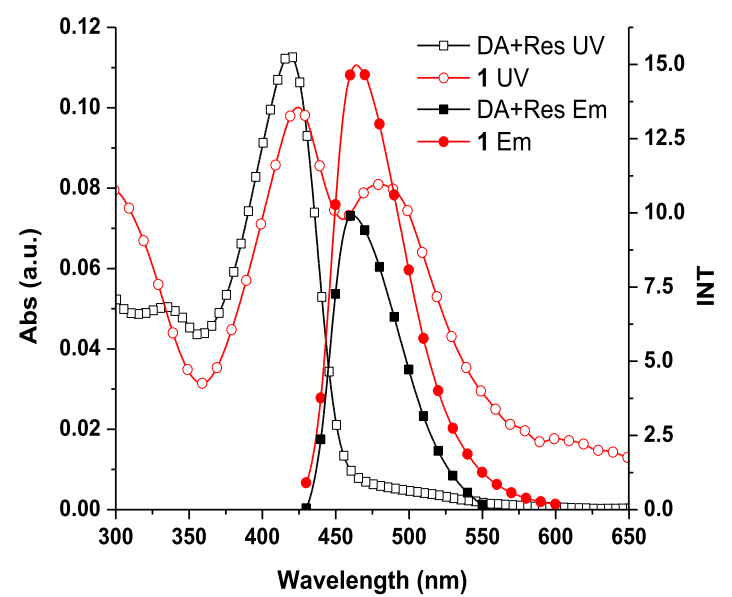

Figure 2. UV-vis and fluorescence spectra of the reaction mixture of 1 at $10 \mu \mathrm{M}$ concentration taken $1 \mathrm{~h}$ under stirring in $0.050 \mathrm{M}$ carbonate buffer, $\mathrm{pH}$ 9.0. For comparison, the spectra of the oxidation reaction of $10 \mu \mathrm{M}$ dopamine with equimolar resorcinol at $1 \mathrm{~h}$ are reported $\left(\lambda_{\mathrm{ex}}: 420\right.$ $\mathrm{nm})$.

when fluorescence development attained a plateau confirmed the presence, besides the starting compound (pseudomolecular ion peak at $m / z 276$ ), of a main species with a pseudomolecular ion peak at $m / z 260$ and an elution time identical to that of the coupling product of dopamine with resorcinol (Figure 3 ). The formation yield of the product from oxidation of $\mathbf{1}$ was comparable but somewhat lower than that obtained from dopamine and resorcinol (Figure S7).

To further support the unexpected identity, the mixture from the autoxidation of $\mathbf{1}$ was chromatographed on a Sephadex G-10 gel filtration column. After a complex brown fraction eluted with the front, probably polymeric in character (detectable laser desorption ionization (LDI)-MS peaks up to $\mathrm{m} / z 1593$, not shown), a more retained yellow band was collected, which displayed a distinct maximum at $420 \mathrm{~nm}$ shifting hypsochromically to $390 \mathrm{~nm}$ with loss of fluorescence upon acidification (Figure S8). LDI-MS analysis of the band gave a pseudomolecular ion peak at $m / z 282[\mathrm{M}+\mathrm{Na}]^{+}$, whereas the ${ }^{1} \mathrm{H} \mathrm{NMR}$ spectrum definitively corroborated its identity with the coupling product of dopamine with resorcinol, following comparison with an authentic sample (Figures S9 and S10). ${ }^{1}$

Figure 4 reports fluorescence intensity from a set of autoxidation reactions run with $\mathbf{1}$ at different concentrations. For comparison, the same spectra were recorded from a 1:1 dopamine-resorcinol mixture at the same concentration. The data indicated a marked deviation from linearity in the fluorescence response with increasing concentration, consistent with a unimolecular fluorogenic process. Apparently, the decrease in emission intensity was concomitant to an increase in the less-retained colored fraction, suggesting competitive polymerization processes. Visually detectable fluorescence was measurable with 1 above a $1 \mu \mathrm{M}$ concentration.

Mechanistic Studies. To address the mechanism of the autoxidative conversion of $\mathbf{1}$ to the fluorescent product, a detailed analysis of the spectrophotometric course of the reaction was initially run. Monitoring of the autoxidation of 1 at $10 \mu \mathrm{M}$ revealed after $30 \mathrm{~min}$ the formation, besides the chromophore at $420 \mathrm{~nm}$, of another species absorbing around $480 \mathrm{~nm}$. This species peaked at $60 \mathrm{~min}$ and then slowly decreased, suggesting an intermediate in the pathway (Figure $5 \mathrm{~A}, \mathrm{~B})$. To gain insight into the nature of this intermediate 

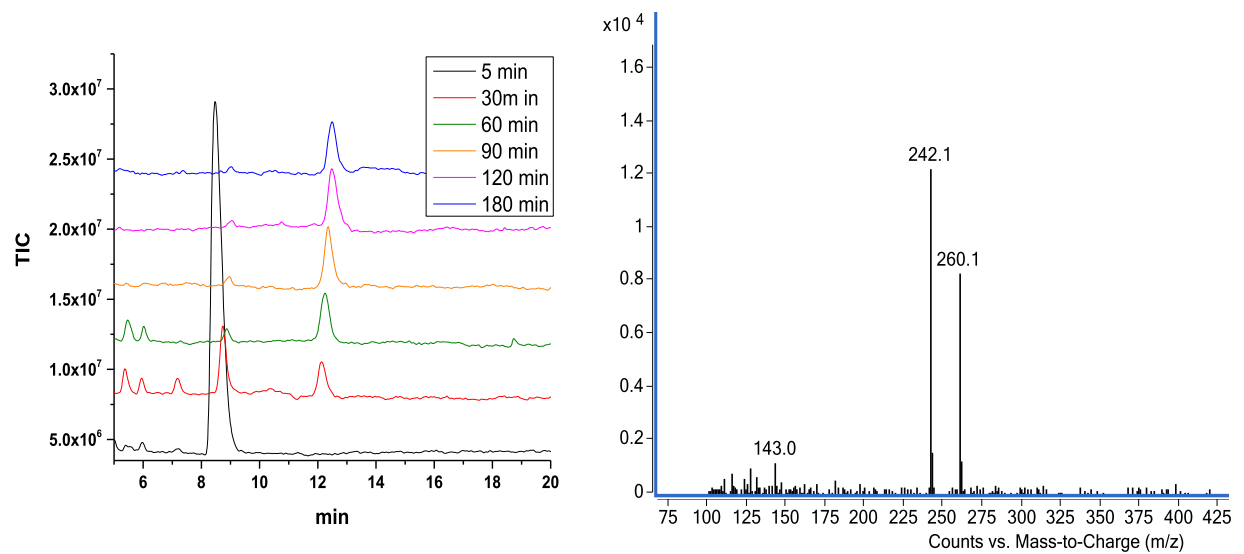

Figure 3. Left: LC-MS $\left(\mathrm{ESI}^{+}\right)$analysis of the oxidation mixtures of $\mathbf{1}(1 \mathrm{mM})$ at different reaction times. For analysis, aliquots were withdrawn and diluted up to $0.05 \mathrm{mg} / \mathrm{mL}$ in $0.1 \%$ formic acid-methanol $(1: 1 \mathrm{v} / \mathrm{v})$. Right: $\mathrm{ESI}^{+}-\mathrm{MS}$ spectrum of the species eluted at $12.2 \mathrm{~min}$. The base peak at $m / z$ 242 is probably due to loss of water.

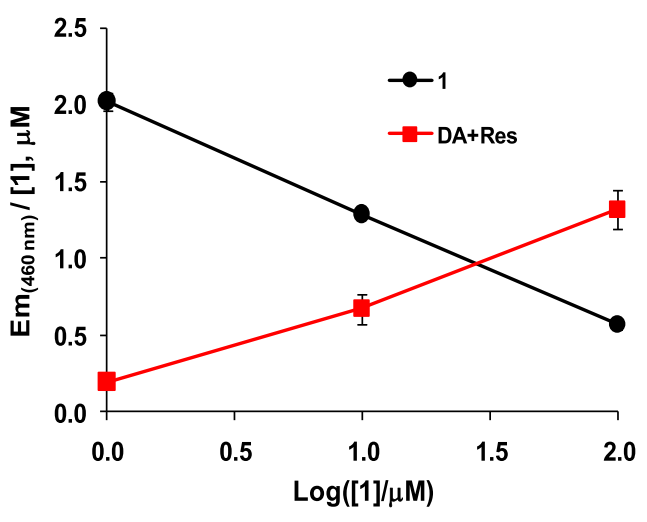

Figure 4. Emission properties of $\mathbf{1}$ following autoxidation at different concentrations $\left(\lambda_{\mathrm{ex}}: 420 \mathrm{~nm}, \lambda_{\text {anal }}: 460 \mathrm{~nm}, \mathrm{pH} 9.0\right)$.

species, which was not observed in the oxidative dopamineresorcinol coupling, the reaction of the model substrate 4methylcatechol, to which cyclization was precluded, with resorcinol was investigated spectrophotometrically. Data in Figure 5A (inset) and Figure S11 indicate formation of a major species absorbing at $480 \mathrm{~nm}$ and devoid of fluorescence. Although it was not possible to isolate and characterize this latter species because of its instability, both computed absorption spectra and predicted $\mathrm{p} K_{\mathrm{a}}$ values allowed to confidently assign it the structure of the expected dibenzofuran coupling product in the phenolate anion form (Figure 6, Sections S1 and S2 pages S11-S19).

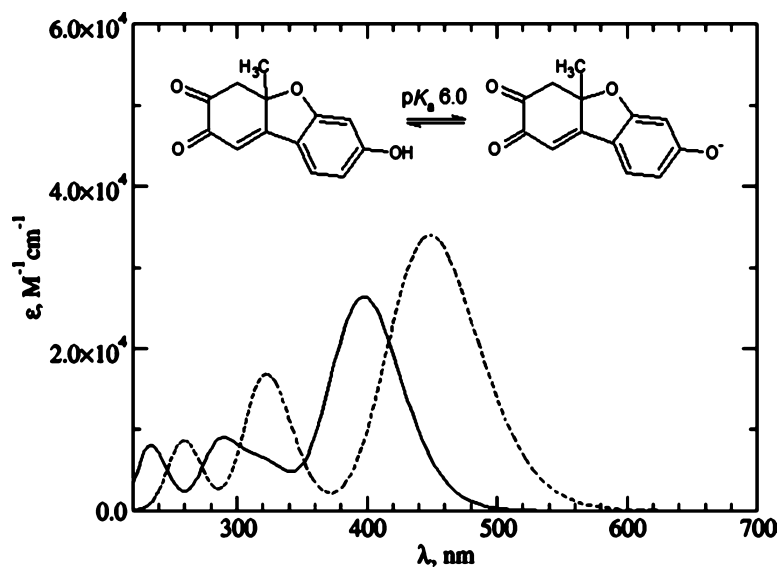

Figure 6. Computed UV-vis spectra of the most significant tautomers/ conformers of the model dibenzofuran products. Full line: neutral form, keto tautomer; dashed line, monoanionic (phenate) form, keto tautomer.

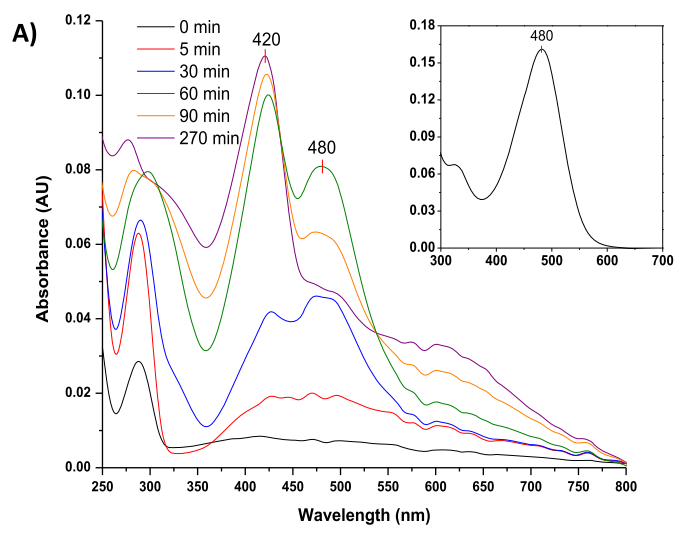

B)

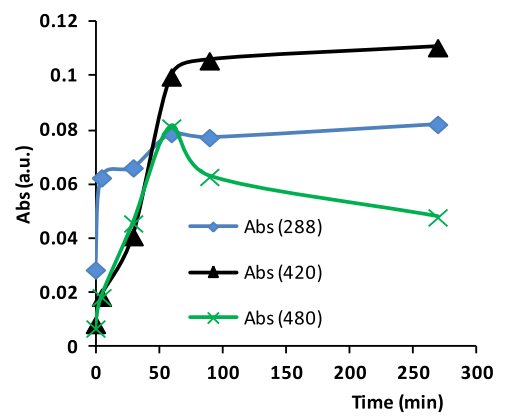

Figure 5. (A) Spectrophotometric analysis of the autoxidation of $10 \mu \mathrm{M}$ 1. Inset: Chromophore developed by autoxidation of $25 \mu \mathrm{M} 4-\mathrm{methylcatechol}$ with equimolar resorcinol (90 min reaction time). (B) Time-course analysis of the autoxidation of $10 \mu \mathrm{M} 1$ at different wavelengths $\left(\lambda_{\text {anal }}: 288,420\right.$, and $480 \mathrm{~nm}$ ). 
On this basis, a mechanism was proposed for the generation of the fluorophore, which involved a complex rearrangement process from 1 driven by loss of a carbon atom shown in Scheme 3. The proposed scheme, which resembles the biosynthetic

Scheme 3. Proposed Mechanism of Conversion of 1 to the Methanobenzofuroazocinone Product ${ }^{a}$

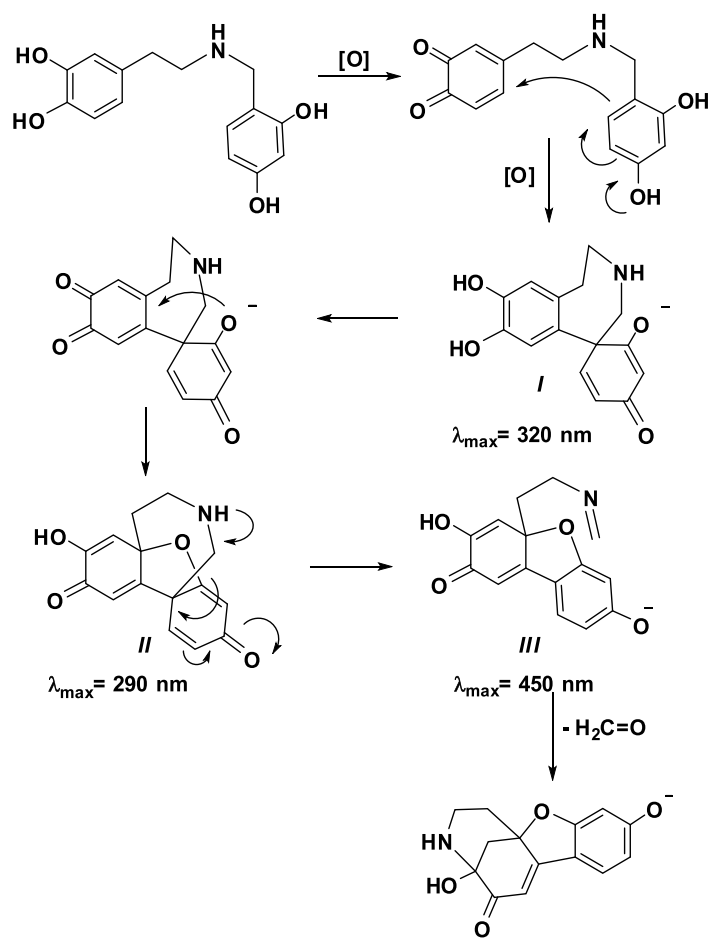

${ }^{a}$ Predicted absorption maxima (DFT calculations) for the main putative intermediates are reported. pathway leading to matlaline from coatline $\mathrm{B},{ }^{3}$ envisaged as the initial step the attack of the activated quaternary carbon of the resorcinol moiety onto the $o$-quinone ring to give a spiro intermediate (I) (Scheme 3). Attack of the phenolic oxygen in the spiro intermediate on the quinone system would lead to closure of the furan ring, leading to a second spiro intermediate (II) that could release the strain in the congested polycyclic scaffold via an amine-promoted cleavage of the methyleneresorcinol bond driven by re-aromatization of the resorcinol ring yielding III. Alternatively, this latter step may also precede furan ring-closure (Scheme S6). Hydrolytic release of formaldehyde liberating the amino group essential for the final ring closing yielding the fluorophore would represent the last step of either route that accounts for the carbon loss accompanying the oxidation reaction. Several efforts were made to get direct evidence for the formation of formaldehyde, including NMR analysis of the reaction mixture over time and search for products arising from trapping of this reactive species by reaction with $\mathbf{1}$ as observed in our previous studies in which the formation of an isoquinoline arising by reaction of dopamine with formaldehyde was observed. ${ }^{10}$ Yet, no conclusive result could be obtained in this case and hence the proposed mechanism remains speculative though chemically sound and supported by literature data.

Scheme 3 highlights the main prototropic forms predicted to prevail under the reaction conditions based on calculated $\mathrm{p} K_{\mathrm{a}}$ 's (Sections S3 and S4 in the Supporting Information, pages S20-S28). The proposed scheme was supported by various lines of evidence.

First, $\mathrm{LC}-\mathrm{MS}\left(\mathrm{ESI}^{+}\right)$monitoring of the reaction course gave extracted ion chromatograms characterized by a minor species at $\mathrm{m} / z 274$ and another more retained species at $\mathrm{m} / \mathrm{z} 272$, compatible with the initial seven-membered spiro intermediate I (calcd exact mass $m / z$ 273.10) and the highly constrained species II preceding the nitrogen-assisted ring opening re-
A)

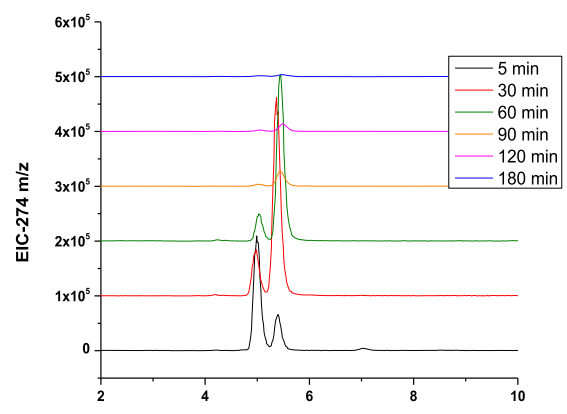

B)

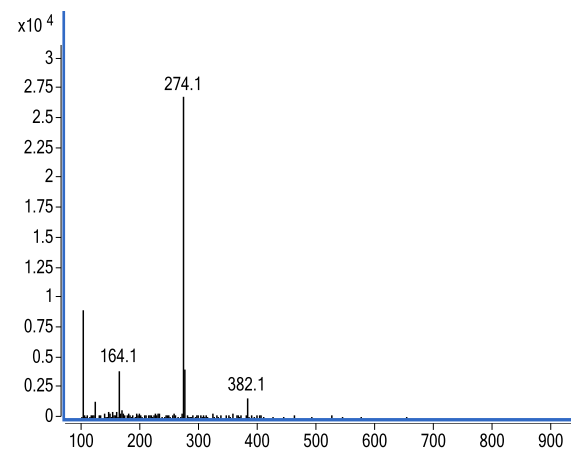

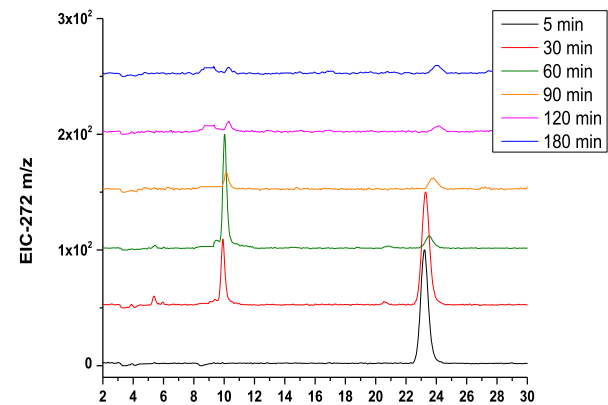

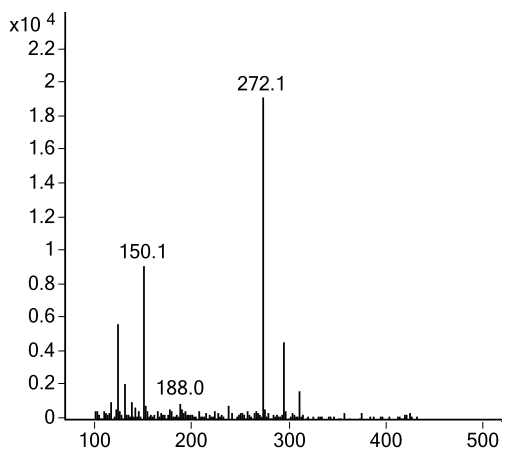

Figure 7. (A) Extracted ion chromatograms at different reaction times $m / z 274$ (left) and $m / z 272$ (right). (B) ESI ${ }^{+}$-MS spectra of the species eluting at $R_{\mathrm{t}}=5.0$ or $5.25 \mathrm{~min}$ (left) and $R_{\mathrm{t}}=10$ or $23 \mathrm{~min}$ (right). 
aromatization of the resorcinol moiety (calcd exact mass at $\mathrm{m} / \mathrm{z}$ 271.08), respectively (Figures 7 and S17-S20).

Second, density functional theory (DFT) analysis of the main intermediates in the proposed scheme predicted for the last intermediate III an absorption maximum at $450 \mathrm{~nm}$ compatible with the $480 \mathrm{~nm}$ band in Figure 3. Persistence of the chromophore at $480 \mathrm{~nm}$ during the reaction could then be attributed to the slow hydrolysis of the imine moiety at alkaline $\mathrm{pH}$. This finding, coupled with the markedly different absorption profile calculated for the coupling product prior to furan ring closure (Section S5 pages S29-S43), suggested that oxygen attack on the quinone ring occurs early in the pathway, thus favoring the route shown in Scheme 3.

As expected, the $\mathrm{O}$-methyl derivative of $\mathbf{1}$ on the catechol functionality, 2 (Scheme 2), did not lead to detectable emission under the same conditions, indicating that oxidative generation of the quinone was critical to fluorescence turn-on.

Sensing Properties of 1 . In separate experiments the potential of $\mathbf{1}$ for various applications was briefly explored. Initially, the fluorescence response of $\mathbf{1}$ to ammonia or amines was investigated in bio-based hydrogels. Figure 8 (panel A,

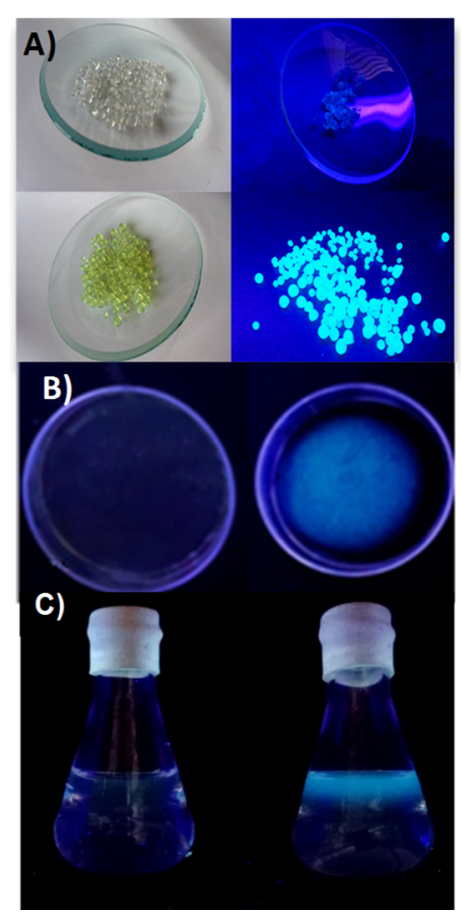

Figure 8. Fluorescence response of $\mathbf{1}(0.1 \mathrm{mM})$. (A) Alginate beads following exposure to ammonia vapors, $(t=10 \mathrm{~min})$ left, under natural light; right, under $365 \mathrm{~nm}$ lamp, top control in the absence of $\mathbf{1}$, and bottom in the presence of 1 . (B) Alginate hydrogel films exposed to vapors from decomposing fish fillets, $t=0 \mathrm{~h}$ (left) and $t=24 \mathrm{~h}$ (right); (C) $0.1 \mathrm{mM} 1$ in $0.05 \mathrm{M}$ carbonate buffer, $\mathrm{pH} 8.5$, under an argon atmosphere before (left) and after (right) injection of air $(t=2 \mathrm{~h})$. Pictures in (B) and (C) were taken under a $365 \mathrm{~nm}$ lamp.

bottom) shows the rapid development of a strong fluorescence in beads of alginate hydrogel prepared in the presence of $0.1 \mathrm{mM}$ 1 upon exposure to gaseous ammonia in a closed chamber at room temperature. To probe the efficiency of fluorescence turnon in the presence of a potentially interfering biological matrix, compound $\mathbf{1}(0.1 \mathrm{mM})$ was added to raw chicken egg white $(\mathrm{pH}$ ca. 9.0) under vigorous stirring. A rapid oxygen-dependent generation of a strong fluorescence was observed in support of an efficient intramolecular coupling even in the presence of the biological components of egg white (Figure S21). The fluorescence developed from an equimolar mixture of dopamine and resorcinol at two different concentrations is also shown for comparison (Figure S21).

As the generation of amine-containing volatiles (e.g., $\mathrm{NH}_{3}$ and $\mathrm{NMe}_{3}$ ) is a major index of food spoilage because of microbial growth, ${ }^{11,12}$ alginate hydrogel films loaded with 1 were exposed to vapors from decomposing fish fillets for $24 \mathrm{~h}$ at room temperature in a closed chamber. Control experiments were conducted at $-20{ }^{\circ} \mathrm{C}$ or at room temperature in the absence of fish fillets. A fluorescence response was noticed under fish decomposition conditions (Figure 8, panel B), but not in the controls (Figure S22), suggesting the potential utility of this reaction for expedient monitoring of packaged fish quality. Compared to colorimetric $\mathrm{pH}$ indicators that are commonly used to monitor food microbial spoilage, ${ }^{13}$ the reaction based on conjugate 1 would have the advantage of a turn-on of fluorescence with increasing $\mathrm{pHs}$, acting in addition as oxygen sensor.

Figure 8 (panel C) shows the potential of 1 as an oxygenresponsive system. Injection of $1 \mathrm{~mL}$ of air via a syringe into the headspace of a sealed flask containing an alkaline solution of 1 kept under a rigorously oxygen-free atmosphere was found to cause a well-detectable emission. This observation suggests the possible use of this system as an oxygen sensor, for example, for package leak detection.

Finally, the ability of $\mathbf{1}$ to serve as an antioxidant capable of scavenging reactive oxygen species with fluorescence read-out was explored. To this aim, the autoxidation of 1,2,3trihydroxybenzene (pyrogallol, $\mathrm{PG}$ ) at $\mathrm{pH} 9.0$ was selected as an established model reaction for the production of superoxide anion by reduction of molecular oxygen by PG. The ability of 1 to act as scavenger of superoxide anion was measured based on development of a blue formazan dye by reduction of a tetrazolium compound (Figure S23). ${ }^{14}$

Data in Figure 9 show that $\mathbf{1}$ can efficiently scavenge superoxide in a dose-dependent manner and the effect is accompanied by a rapid fluorescence turn-on as a measurable record of antioxidant activity.

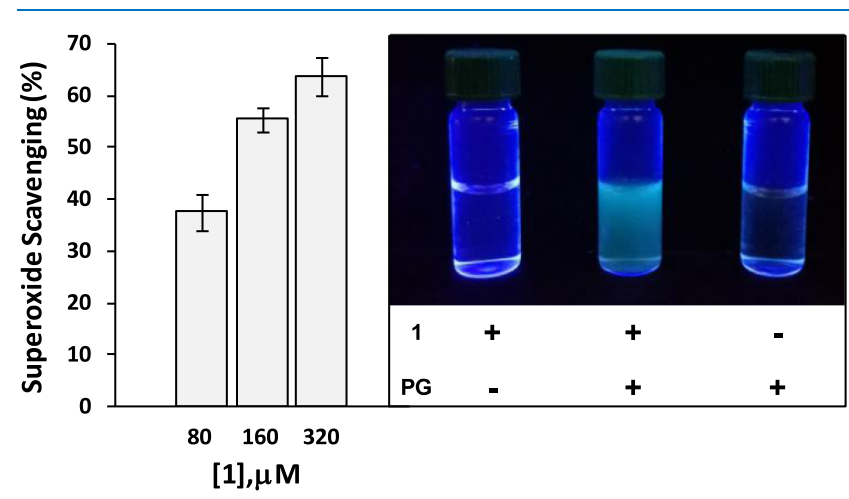

Figure 9. Left: Dose-dependent superoxide scavenging activity of $\mathbf{1}$ in the presence of $160 \mu \mathrm{M}$ PG as determined by the nitroblue tetrazolium assay (means of three different experiments \pm standard deviation). Right: Digital picture of oxidation mixtures of $160 \mu \mathrm{M} 1$ at $\mathrm{pH} 9.0$ under a $365 \mathrm{~nm}$ lamp in the absence or in the presence of equimolar PG, after $2 \mathrm{~min}$ 


\section{CONCLUSIONS}

We have disclosed herein a unimolecular variant of the dopamine-resorcinol reaction leading to the methanobenzofuroazocinone fluorophore from the conjugate $\mathbf{1}$, for which we propose the term "FluoResCat". Alkali-promoted fluorescence turn-on from 1 was proposed to proceed via highly strained spirocyclic intermediates whose evolution may be accompanied by hydrolytic release of formaldehyde accounting for carbon loss. The FluoResCat system is efficient, versatile, develops from a cheap and easily available precursor, is endowed with antioxidant properties, and operates under mild conditions. It may be useful as oxygen/superoxide scavenger with fluorescence read-out of activity and can be used in complex biomatrices, such as chicken egg white, or in hydrogels for the sensing of oxygen or volatile amines, for example, for smart packaging applications. These latter appear most suitable also in consideration of the relatively slow fluorescence turn-on from oxidation of 1 . It could be possible, for example, to assess whether spoilage has occurred because of loss of vacuum, exposure to oxygen, by simply exposing the package to a UV lamp. Compared to the parent bimolecular dopamine-resorcinol system, the unimolecular variant disclosed here expands the current tool-box of catecholbased functional systems ${ }^{15}$ and appears to be highly advantageous in terms of sensitivity, risk of interference by intermolecular processes in complex media and, especially, antioxidant activity.

The results of this study are of interest also in relation to the increasing demand of systems for fluorescence-based imaging and sensing ${ }^{16,17}$ based on robust and versatile chromophores responding to specific stimuli with a strong emission. Reactivitybased turn-on systems usually exploit cleavage reactions, ${ }^{18}$ click chemistry cyclizations, ${ }^{19}$ organic couplings, ${ }^{20}$ metal-ligand substitution, ${ }^{21}$ and tandem cascades unmasking fluorogenic scaffolds ${ }^{16,22}$ but none of the most popular systems, to the best of our knowledge, relies for the fluorescence response on a spontaneous alkali-promoted oxidation step. From this perspective, $\mathbf{1}$ may provide a novel promising prototype for a range of applications also in biological media.

\section{EXPERIMENTAL SECTION}

General Information. All solvents and reagents were obtained from commercial sources and used without further purification. Buffers were prepared by standard procedures. A Crison $\mathrm{pH}$-meter equipped with a 5014 Crison electrode was used for $\mathrm{pH}$ measurements at room temperature. UV-vis absorption spectra were registered at room temperature on a $\mathrm{V}$ 560 JASCO spectrophotometer using calibrated $2 \mathrm{~mL}$ quartz cuvettes. Steady-state fluorescence emission spectra were recorded with a FP-750 JASCO spectrofluorometer. ${ }^{1} \mathrm{H}$ NMR and ${ }^{13} \mathrm{C}$ NMR spectra were recorded in deuterated solvents at $400 \mathrm{MHz}$ on a Bruker DRX 400 or Bruker AVANCE DRX 400, $\delta$ values are reported in ppm, and coupling constants are given in hertz. HPLC analyses for reaction monitoring were performed on an Agilent 1100 series instrument equipped with an LC10AD VP pump and a G1314A UV-visible detector using a SphereClone $\mathrm{C}_{18}$ column $(4.6 \times 150 \mathrm{~mm}, 5 \mu \mathrm{m}) ; 0.1 \%$ formic acid-methanol 8:2 was selected as the eluting system, at 0.7 $\mathrm{mL} / \mathrm{min}$ flux. LC-MS analysis was conducted on an ESI-TOF 1260/6230DA Agilent Technologies in positive ion mode using a Zorbax Eclipse Plus $\mathrm{C}_{18}$ column $(4.6 \times 150 \mathrm{~mm}, 5 \mu \mathrm{m}) ; 0.1 \%$ formic acid-methanol 8:2 was selected as the eluting system at $0.4 \mathrm{~mL} / \mathrm{min}$ flux. LDI mass spectrometric analyses were run on an AB Sciex TOF/TOF 4800 instrument loading the samples on the plate at $1 \mathrm{mg} / \mathrm{mL}$ in methanol. Spectra represent the sum of 15000 laser pulses from randomly chosen spots per sample position. Raw data were analyzed using the computer software provided by the manufacturers and are reported as monoisotopic masses.

Synthesis of 1. A mixture of dopamine hydrochloride $(0.25$ g, $1.32 \mathrm{mmol}$ ) and 2,4-dihydroxybenzaldehyde (0.18 g, 1.32 $\mathrm{mmol})$ in methanol $(31 \mathrm{~mL})$ was stirred at room temperature. After complete dissolution, triethylamine $(0.25 \mathrm{~mL}, 1.72 \mathrm{mmol})$ was slowly added via a syringe. The reaction was left overnight under stirring. After removal of the solvent under reduced pressure, the desired Schiff base was obtained as a yellow oil in $83 \%$ yield. The oil was rinsed in glacial acetic acid at $10 \mathrm{mM}$ and reduced with $\mathrm{NaBH}_{4}$ (3 molar equiv). When evolution of hydrogen had ceased, the mixture was dried under vacuum, then rinsed in $1 \mathrm{~mL}$ of water, and $3 \mathrm{M} \mathrm{HCl}$ was added to $\mathrm{pH} 2.0$. Desalting of the mixture was carried out on Dowex resin 50WX4 using a gradient of $\mathrm{HCl}$ from 0.5 to $3 \mathrm{M}$ as the eluant. Fractions were collected and analyzed by UV-vis spectrophotometry. The desired product was eluted in $3 \mathrm{M} \mathrm{HCl}$.

Schiff Base. $R_{\mathrm{f}}=0.6\left(\mathrm{CHCl}_{3}-\mathrm{CH}_{3} \mathrm{OH}\right.$ 9:1). UV-vis $\left(\mathrm{CH}_{3} \mathrm{OH}\right): \lambda_{\max }, \mathrm{nm}(\log \varepsilon): 301$ (4.47), $370(4.09) ;{ }^{1} \mathrm{H}$ NMR (400 MHz, methanol- $\left.d_{4}\right): \delta 7.90(\mathrm{~s}, 1 \mathrm{H}), 7.01(\mathrm{~d}, J=8.8$ $\mathrm{Hz}, 1 \mathrm{H}), 6.69(\mathrm{~d}, J=8.3 \mathrm{~Hz}, 1 \mathrm{H}), 6.67(\mathrm{~s}, \mathrm{~d}, J=1.7 \mathrm{~Hz}, 1 \mathrm{H})$, $6.55(\mathrm{dd}, J=7.8,1.7 \mathrm{~Hz}, 1 \mathrm{H}), 6.12(\mathrm{~d}, J=8.8 \mathrm{~Hz}, 1 \mathrm{H}), 6.06(\mathrm{~s}$, $1 \mathrm{H}), 3.74(\mathrm{t}, J=6.6 \mathrm{~Hz}, 2 \mathrm{H}), 2.84(\mathrm{t}, J=6.6 \mathrm{~Hz}, 2 \mathrm{H}) .{ }^{13} \mathrm{C} \mathrm{NMR}$ $\left(101 \mathrm{MHz}\right.$, methanol- $\left.d_{4}\right): \delta 167.7,165.3,146.5,145.2,136.9$, $130.7,121.4,117.1,116.6,111.2,108.3,54.6,37.1$.

4-(2-((2,4-Dihydroxybenzyl)amino)ethyl)benzene-1,2-diol (1). Off-white amorphous solid $(0.28 \mathrm{~g}$, yield $=95 \%)$. Product purity $>90 \%$ was assessed by HPLC and proton NMR analysis, $R_{\mathrm{t}}=15 \mathrm{~min}, 0.1 \% \mathrm{HCOOH}-\mathrm{MeOH}$ 8:2; UV-vis $\mathrm{CH}_{3} \mathrm{OH}$ : $\lambda_{\max } \mathrm{nm}(\log \varepsilon): 280 \mathrm{~nm}$ (3.99); ${ }^{1} \mathrm{H}$ NMR (400 MHz, methanol- $\left.d_{4}\right): \delta 7.05(\mathrm{~d}, J=8.1 \mathrm{~Hz}, 1 \mathrm{H}), 6.69(\mathrm{~d}, J=8.1 \mathrm{~Hz}$, $1 \mathrm{H}), 6.64(\mathrm{~s}, \mathrm{H}-6,1 \mathrm{H}), 6.53(\mathrm{~d}, J=8.1 \mathrm{~Hz}, 1 \mathrm{H}), 6.34(\mathrm{~s}, 1 \mathrm{H})$, $6.29(\mathrm{dd}, J=8.3,1.9 \mathrm{~Hz}, 1 \mathrm{H}), 4.06(\mathrm{~s}, 2 \mathrm{H}), 3.10(\mathrm{t}, J=7.2 \mathrm{~Hz}$, $2 \mathrm{H}), 2.81(\mathrm{t}, J=7.2 \mathrm{~Hz}, 2 \mathrm{H}) ;{ }^{13} \mathrm{C}$ NMR (100 MHz, methanol$\left.d_{4}\right): \delta 161.4,158.6,146.6,145.5,133.4,129.1,121.0,116.7$, 109.7, 108.1, 103.3, 49.3, 47.8, 32.4. MS $\left(\mathrm{ESI}^{+}\right) \mathrm{calcd} m / z[\mathrm{M}+$ $\mathrm{H}]^{+}, 276.1158$; found, 276.1172 .

Synthesis of 2. A mixture of 1-(3,4-dimethoxyphenyl)ethanamine $(0.12 \mathrm{~mL}, 0.72 \mathrm{mmol})$ and 2,4-dihydroxybenzaldehyde $(0.10 \mathrm{~g}, 0.72 \mathrm{mmol})$ in absolute ethanol $(36 \mathrm{~mL})$ was stirred at room temperature for $2 \mathrm{~h}$. Removal of the solvent under reduced pressure afforded the desired imine as a yellow oil in $85 \%$ yield. This latter was then rinsed in glacial acetic acid ( 20 mM) and reduced with $\mathrm{NaBH}_{4}$ (8 equiv). When hydrogen evolution had ceased, the mixture was dried under vacuum. The residue was rinsed in water $(4 \mathrm{~mL})$ and the $\mathrm{pH}$ of the solution was adjusted to $7.0(0.2 \mathrm{M} \mathrm{NaOH})$. Extraction with ethyl acetate $(3 \times 5 \mathrm{~mL})$ and removal of the solvent yielded a mixture of the imine and product 2 . This latter was then purified by silica gel chromatography using $\mathrm{CHCl}_{3} / \mathrm{MeOH}$ 98:2 as the eluent. A complete reduction of the Schiff base was obtained only using a large excess of $\mathrm{NaBH}_{4}$, under which conditions a more complex reaction mixture was obtained (TLC evidence).

Schiff Base. ${ }^{1} \mathrm{H}$ NMR (500 MHz, methanol- $\left.d_{4}\right): \delta 7.81(\mathrm{~s}$, $1 \mathrm{H}), 6.95(\mathrm{~d}, J=8.7 \mathrm{~Hz}, 1 \mathrm{H}), 6.86(\mathrm{~d}, J=8.1 \mathrm{~Hz}, 1 \mathrm{H}), 6.79(\mathrm{~s}$, $1 \mathrm{H}), 6.77(\mathrm{~d}, J=8.1 \mathrm{~Hz}, 1 \mathrm{H}), 6.11(\mathrm{~d}, J=8.7 \mathrm{~Hz}, 1 \mathrm{H}), 3.77(\mathrm{~s}$, $3 \mathrm{H}), 3.74(\mathrm{~s}, 3 \mathrm{H}), 3.75(\mathrm{t}, J=6.6 \mathrm{~Hz}, 2 \mathrm{H}), 2.89(\mathrm{t}, J=6.6 \mathrm{~Hz}$, $2 \mathrm{H}) .{ }^{13} \mathrm{C}$ NMR $\left(101 \mathrm{MHz}\right.$, methanol- $\left.d_{4}\right): \delta 166.2,164.0,157.5$, 
149.1, 147.9, 135.3, 130.7, 121.1, 112.7, 111.9, 109.8, 107.1, $55.2,55.1,53.5,35.9$.

4-((3,4-Dimethoxyphenethylamino)methyl)benzene-1,3diol (2). Colorless oil ( $0.076 \mathrm{~g}, 41 \%$ yield); UV-vis (EtOH, $\mathrm{pH}$ 7.0): $\lambda_{\max } \mathrm{nm}(\log \varepsilon): 278$ (3.74). Product purity $>90 \%$ was assessed by HPLC and proton NMR analysis. HPLC: $R_{\mathrm{t}}=5.57$ $\min \left(1 \% \mathrm{HCOOH}-\mathrm{CH}_{3} \mathrm{OH} 8: 2\right) .{ }^{1} \mathrm{H} \mathrm{NMR}(500 \mathrm{MHz}$, methanol- $\left.d_{4}\right): \delta 7.06(\mathrm{~d}, J=8.1 \mathrm{~Hz}, 1 \mathrm{H}), 6.90(\mathrm{~d}, J=8.4 \mathrm{~Hz}$, $1 \mathrm{H}), 6.80(\mathrm{~s}, 1 \mathrm{H}), 6.77(\mathrm{~d}, J=8.4 \mathrm{~Hz}, 1 \mathrm{H}), 6.41(\mathrm{~s}, 1 \mathrm{H}), 6.30(\mathrm{~d}$, $J=8.1 \mathrm{~Hz}, 1 \mathrm{H}), 4.06(\mathrm{~s}, 2 \mathrm{H}), 3.80(\mathrm{~s}, 6 \mathrm{H}), 3.10(\mathrm{t}, J=7.2 \mathrm{~Hz}$, $2 \mathrm{H}), 2.90(\mathrm{t}, J=7.2 \mathrm{~Hz}, 2 \mathrm{H}) .{ }^{13} \mathrm{C}$ NMR (101 MHz, methanol$\left.d_{4}\right): \delta 162.0,159.8,151.4,150.2,135.2,132.3,123.1,115.1$, 115.0, 114.6, 109.2, 105.0, 58.2, 58.1, 49.9, 47.3, 35.1, $\mathrm{MS}\left(\mathrm{ESI}^{+}\right)$ calcd $m / z[\mathrm{M}+\mathrm{H}]^{+}, 304.1471$; found, 304.1457.

Oxidation Reaction: General Procedure. Solutions of $\mathbf{1}$ in methanol were diluted to the appropriate concentration with $0.05 \mathrm{M} \mathrm{Na}_{2} \mathrm{CO}_{3}$ buffer, $\mathrm{pH} 9.0$, and left under stirring, in air at room temperature until reaction completion as determined spectrophotometrically by monitoring chromophore development. The reaction of equimolar dopamine or 4-methylcatechol with resorcinol or $\mathbf{2}$ was carried out under the same conditions. When needed for NMR analysis, oxidation of 1 at $1 \mathrm{mM}$ was carried out in aerated $0.05 \mathrm{M}$ carbonate buffer, $\mathrm{pH} 9.0$, that had been previously deuterated by repeated exchanges with $\mathrm{D}_{2} \mathrm{O}$.

Purification of the Oxidation Mixture of 1 and Product Analysis. 1 (50 mg, $0.18 \mathrm{mmol}$ ) predissolved in methanol (1 $\mathrm{mL}$ ) was added to $0.05 \mathrm{M}$ carbonate buffer $(180 \mathrm{~mL})$, and the mixture was left under stirring, in air at room temperature. After $3 \mathrm{~h}$, the reaction mixture was concentrated and fractionated on a Sephadex G10 $(10 \times 0.1 \mathrm{~cm})$ column using distilled water as the eluant. The elution was monitored by UV-vis spectroscopy. Four fractions were collected. Fractions 1-3 were brown in color and all showed a broadband absorption. Fraction 4 displayed absorption maxima close to that of 4,9-dihydroxy-3,4dihydro-1H-4,11a-methanobenzofuro[2,3- $d]$ azocin-5(2H)-one obtained from reaction of dopamine with resorcinol. ${ }^{1,4}$ Product identity was secured by LDI-MS and ${ }^{1} \mathrm{H}$ NMR spectral characterization (yield: $12 \mathrm{mg}, 0.05 \mathrm{mmol}, 26 \%$ ).

Experiments with Alginate Hydrogels Incorporating 1. Sodium alginate was dissolved in distilled water $(20 \mathrm{~mL}, 2 \%$ $\mathrm{w} / \mathrm{w})$; then 1 at $22 \mathrm{mM}$ in methanol $(0.09 \mathrm{~mL})$ was added. Beads were prepared by dropping the freshly prepared gel in a $0.1 \mathrm{M}$ solution of $\mathrm{CaCl}_{2}$, allowing alginate reticulation for few minutes and recovery of beads by filtration. Films were fabricated similarly by spreading the gel on a smooth surface followed by dipping in the $\mathrm{CaCl}_{2}$ solution for about $60 \mathrm{~s}$. Exposure to ammonia (at $28 \%$ aqueous solution) or decomposing fish fillets was carried out in sealed glass chambers at room temperature. Control experiments were carried out at $-20{ }^{\circ} \mathrm{C}$ or at room temperature in the absence of fish fillets.

Superoxide Scavenging Assay. ${ }^{14} 1$ (final concentration 80,160 , or $320 \mu \mathrm{M}$ ) was added to $0.05 \mathrm{M}$ ammonium hydrogen carbonate buffer ( $\mathrm{pH} 9.3$ ) containing $0.33 \mathrm{mM}$ EDTA, $10 \mathrm{mM}$ nitroblue tetrazolium (NBT), and $160 \mu \mathrm{M}$ PG. The mixture was taken under vigorous stirring, and after $5 \mathrm{~min}$, the absorbance at $596 \mathrm{~nm}$ was measured. Results were expressed as percentage of the ratio of the absorbance at $596 \mathrm{~nm}$ of a given mixture with respect to that of the control mixture run in the absence of the sample. Experiments were run in triplicate.

Computational Methods. All DFT calculations were performed with the Gaussian package of programs. ${ }^{23}$ Structures were geometry-optimized at the DFT level, with a hybrid functional $(\mathrm{PBE} 0)^{24}$ and a reasonably large basis set [6-
$31+G(d, p)]$. For each species, different tautomers/conformers as well as different protonation states were explored. In those cases where conformational enantiomers exist, a single enantiomeric series has been examined. Computations were performed either in vacuo or by adoption of a polarizable continuum medium to account for the influence of the solution environment. ${ }^{25}$ Nonelectrostatic contributions to the solvationfree energy were accounted for in single-point calculations employing radii and nonelectrostatic terms of the solvation model based on density (SMD) solvation model. ${ }^{26}$ Vibrationalrotational contributions to the free energy were also computed. UV-vis spectra of the main species were computed in vacuo or in solution using the time-dependent DFT approach, ${ }^{27}$ with the PBE0 functional and the $6-311++\mathrm{G}(2 \mathrm{~d}, 2 \mathrm{p})$ basis set. To produce graphs, transitions below $5.6 \mathrm{eV}$ were selected, and an arbitrary Gaussian line width of $0.25 \mathrm{eV}$ was imposed; the spectra were finally converted to a wavelength scale.

\section{ASSOCIATED CONTENT}

\section{S Supporting Information}

The Supporting Information is available free of charge on the ACS Publications website at DOI: 10.1021/acsomega.8b02778.

Spectral data, LC-MS analysis of the oxidation reaction of 1; UV-vis and fluorescence spectra of 1 and model compounds; mechanistic scheme, fluorogenic reaction of $\mathbf{1}$ in crude chicken egg white, and control experiments; computational investigation of structural and spectroscopic properties including UV-vis spectra and $\mathrm{p} K_{\mathrm{a}}$ 's of postulated intermediates and reaction products; complete ref 23 (PDF)

\section{AUTHOR INFORMATION}

\section{Corresponding Author}

*E-mail: alesnapo@unina.it.

ORCID $\odot$

Orlando Crescenzi: 0000-0002-4413-4743

Marco d'Ischia: 0000-0002-7184-0029

Alessandra Napolitano: 0000-0003-0507-5370

Notes

The authors declare no competing financial interest.

\section{REFERENCES}

(1) Crescenzi, O.; Napolitano, A.; Prota, G.; Peter, M. G. Oxidative coupling of DOPA with resorcinol and phloroglucinol: isolation of adducts with an unusual tetrahydromethanobenzofuro[2,3-d]azocine skeleton. Tetrahedron 1991, 47, 6243-6250.

(2) Acuña, A. U.; Amat-Guerri, F. Early history of solution fluorescence: the lignum nephriticum of Nicolás Monardes. Springer Ser. Fluoresc. 2008, 4, 3-20.

(3) Acuña, A. U.; Amat-Guerri, F.; Morcillo, P.; Liras, M.; Rodrìguez, B. Structure and formation of the fluorescent compound of lignum nephriticum. Org. Lett. 2009, 11, 3020-3023.

(4) Acuña, A. U.; Álvarez-Pérez, M.; Liras, M.; Coto, P. B.; AmatGuerri, F. Synthesis and photophysics of novel biocompatible fluorescent oxocines and azocines in aqueous solution. Phys. Chem. Chem. Phys. 2013, 15, 16704-16712.

(5) (a) Zhang, X.; Zhu, Y.; Li, X.; Guo, X.; Zhang, B.; Jia, X.; Dai, B. A simple, fast and low-cost turn-on fluorescence method for dopamine detection using in situ reaction. Anal. Chim. Acta 2016, 944, 51-56. (b) Zhao, J.; Bao, X.; Wang, S.; Lu, S.; Sun, J.; Yang, X. In situ fluorogenic and chromogenic reactions for the sensitive dual-readout assay of tyrosinase activity. Anal. Chem. 2017, 89, 10529-10536. (c) Zhao, J.; Wang, S.; Lu, S.; Bao, X.; Sun, J.; Yang, X. An enzyme 
cascade-triggered fluorogenic and chromogenic reaction applied in enzyme activity assay and immunoassay. Anal. Chem. 2018, 90, 77547760.

(6) Nador, F.; Novio, F.; Ruiz-Molina, D. Coordination polymer particles with ligand-centred $\mathrm{pH}$-responses and spin transition. Chem. Commun. 2014, 50, 14570-14572.

(7) Kamal-Eldin, A.; Pouru, A.; Eliasson, C.; Åman, P. Alkylresorcinols as antioxidants: hydrogen donation and peroxyl radical-scavenging effects. J. Sci. Food Agric. 2001, 81, 353-356.

(8) Bendary, E.; Francis, R. R.; Ali, H. M. G.; Sarwat, M. I.; El Hady, S. Antioxidant and structure-activity relationships (SARs) of some phenolic and anilines compounds. Ann. Agric. Sci. 2013, 58, 173-181.

(9) Miessner, M.; Crescenzi, O.; Napolitano, A.; Prota, G.; Andersen, S. O.; Peter, M. G. Biphenyltetrols and dibenzofuranones from oxidative coupling of resorcinols with 4-alkylpyrocatechols: new clues to the mechanism of insect cuticle sclerotization. Helv. Chim. Acta 1991, $74,1205-1212$.

(10) Napolitano, A.; Pezzella, A.; Prota, G. 6,7-Dihydroxy-1,2,3,4tetrahydroisoquinoline formation by iron mediated dopamine oxidation: a novel route to endogenous neurotoxins under oxidative stress conditions. Tetrahedron Lett. 1999, 40, 2833-2836.

(11) Kuswandi, B.; Jayus; Restyana, A.; Abdullah, A.; Heng, L. Y.; Ahmad, M. A novel colorimetric food package label for fish spoilage based on polyaniline film. Food Control 2012, 25, 18-189.

(12) Bhadra, S.; Narvaez, C.; Thomson, D. J.; Bridges, G. E. Nondestructive detection of fish spoilage using a wireless basic volatile sensor. Talanta 2015, 134, 718-723.

(13) Ma, Q.; Ren, Y.; Gu, Z.; Wang, L. Developing an intelligent film containing Vitis amurensis husk extracts: The effects of $\mathrm{pH}$ value of the film-forming solution. J. Cleaner Prod. 2017, 166, 851-859.

(14) Xu, C.; Liu, S.; Liu, Z.; Song, F.; Liu, S. Superoxide generated by pyrogallol reduces highly water-soluble tetrazolium salt to produce a soluble formazan: a simple assay for measuring superoxide anion radical scavenging activities of biological and abiological samples. Anal. Chim. Acta 2013, 793, 53-60.

(15) Yang, J.; Stuart, M. A. C.; Kamperman, M. Jack of all trades: versatile catechol crosslinking mechanisms. Chem. Soc. Rev. 2014, 43, $8271-8298$

(16) Chan, J.; Dodani, S. C.; Chang, C. J. Reaction-based smallmolecule fluorescent probes for chemoselective bioimaging. Nat. Chem. 2012, 4, 973-984.

(17) Jun, M. E.; Roy, B.; Ahn, K. H. "Turn-on” fluorescent sensing with "reactive" probes. Chem. Commun. 2011, 47, 7583-7601.

(18) (a) Liang, L.; Lan, F.; Li, L.; Su, M.; Ge, S.; Yu, J.; Liu, H.; Yan, M. Fluorescence "turn-on" determination of $\mathrm{H}_{2} \mathrm{O}_{2}$ using multilayer porous $\mathrm{SiO}_{2} / \mathrm{NGQDs}$ and PdAu mimetics enzymatic/oxidative cleavage of single-stranded DNA. Biosens. Bioelectron. 2016, 82, 204-211. (b) Santra, M.; Ko, S.-K.; Shin, I.; Ahn, K. H. Fluorescent detection of palladium species with an o-propargylated fluorescein. Chem. Commun. 2010, 46, 3964-3966.

(19) (a) Jewett, J. C.; Bertozzi, C. R. Synthesis of a fluorogenic cyclooctyne activated by Cu-free click Chemistry. Org. Lett. 2011, 13, 5937-5939. (b) Qi, J.; Han, M.-S.; Chang, Y.-C.; Tung, C.-H. Developing visible fluorogenic "click-on" dyes for cellular imaging. Bioconjugate Chem. 2011, 22, 1758-1762. (c) Ji, X.; Ji, K.; Chittavong, V.; Aghoghovbia, R. E.; Zhu, M.; Wang, B. Click and fluoresce: a bioorthogonally activated smart probe for wash-free fluorescent labeling of biomolecules. J. Org. Chem. 2017, 82, 1471-1476.

(20) Isik, M.; Ozdemir, T.; Turan, I. S.; Kolemen, S.; Akkaya, E. U. Chromogenic and fluorogenic sensing of biological thiols in aqueous solutions using BODIPY-based reagents. Org. Lett. 2012, 15, 216-219.

(21) Gui, S.; Huang, Y.; Hu, F.; Jin, Y.; Zhang, G.; Yan, L.; Zhang, D.; Zhao, R. Fluorescence turn-on chemosensor for highly selective and sensitive detection and bioimaging of $\mathrm{Al}^{(3+)}$ in living cells based on ioninduced aggregation. Anal. Chem. 2015, 87, 1470-1474.

(22) Loudet, A.; Burgess, K. BODIPY dyes and their derivatives: synthesis and spectroscopic properties. Chem. Rev. 2007, 107, 48914932.
(23) Frisch; et al. Gaussian 09, Revision D.01; Gaussian, Inc.: Wallingford CT, 2013. For complete reference see SI page S55.

(24) Adamo, C.; Barone, V. Toward Reliable density functional methods without adjustable parameters: the PBE0 model. J. Chem. Phys. 1999, 110, 6158-6170.

(25) Tomasi, J.; Mennucci, B.; Cammi, R. Quantum mechanical continuum solvation models. Chem. Rev. 2005, 105, 2999-3094.

(26) Marenich, A. V.; Cramer, C. J.; Truhlar, D. G. Universal solvation model based on solute electron density and on a continuum model of the solvent defined by the bulk dielectric constant and atomic surface tensions. J. Phys. Chem. B 2009, 113, 6378-6396.

(27) Casida, M. E.; Jamorski, C.; Casida, K. C.; Salahub, D. R. Molecular excitation energies to high-lying bound states from timedependent density-functional response theory: characterization and correction of the time-dependent local density approximation ionization threshold. J. Chem. Phys. 1998, 108, 4439-4449. 